
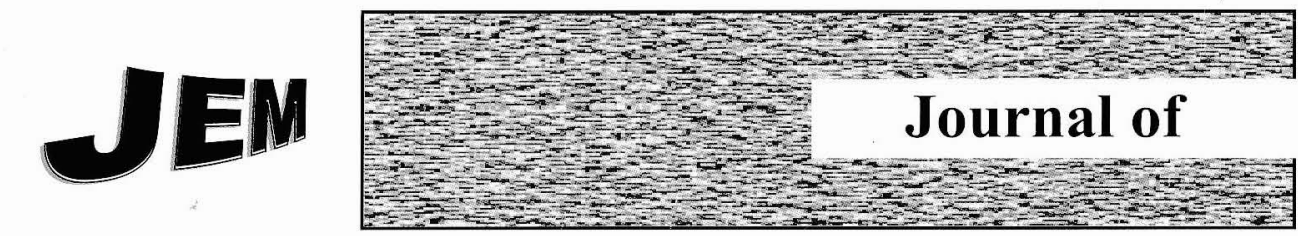

EDucational Management

A Bi-annual Publication of

THE INSTITUTE FOR EDUCATIONAL PLANNING AND ADMINISTRATION

(IEPA)

University of Cape Coast, Ghana

ISSN 0855 - $3343 \quad$ Vol. $6 \quad$ Nov. 2012 


\title{
Crisis Management in Senior High Schools in the Cape Coast Metropolis
}

\author{
Michael Amakyi
}

\section{Abstract}

The study examined crisis management in senior high schools in the Cape Coast metropolis. A basic interpretive study was conducted to gather data from heads of senior high schools in Cape Coast. The study revealed that the schools remain largely unprepared to handle crisis. Also, the study informants indicated that the schools do not have crisis management plans and do adopt reactive measures in addressing crisis. Policy recommendations included the development of crisis management plan as an integral part of the strategic plans of the schools. Research recommendations included replicating this study in other GES designated districts and metropolis to determine if findings reported here are typical for the entire country.

\section{Introduction}

Institutions inevitably experience crises and schools have not been spared. Crises are not limited to one sector of society, but rather all are affected. Pauchant and Mitroff (1992) see a crisis as a disruption affecting how an entity functions; posing threat to its basic assumptions, its subjective sense of self, and its existential core. A crisis in a school infringes upon the school day and impacts how the school carries out its mission.
Ordinarily, schools have wellstructured programmes and function with great efficiency under normal conditions. However, schools face unusual demands during crisisunexpected and unpredictable influences from school board members, parents, other major stakeholders, and the media. Life in the school changes as staff members and students are personally and collectively affected by the crisis. During crises major facets of a school's functioning are likely to be jeopardized.

Crises in schools place greater responsibilities on the shoulders of the administrators. In addition to dealing with the crisis and responding to the demands of the school public, especially the media, school administrators have to keep the school running. Expectedly, school administrators are to deal with crises quickly and effectively, nevertheless, "many school officials remain unprepared to deal with most types of potential crises" (Kowalski, 2008, p. 29). Preparedness to effectively deal with crisis becomes paramount to the smooth running of the school. Crisis, whether it occurs before, during, or after the official school hours, affects the operations of the school. It is thus important that school authorities adopt proactive measures to address crisis instead of fire-fighting measures in dealing with crisis (Gainey, 2009). 


\section{Problem Statement}

During the last two decades schools have experienced crises that captured the attention of society. Kowalski (2010) points out that crisis in schools range in scope and intensity and can affect only an individual or an entire community. Whether it is food poisoning, disease outbreak, death of a student or staff, a natural disaster (e.g., fire or flood), negative media publication, or an act of real or threatened violence, These crises that can occur in a school remind society that although schools are relatively safe environments, they are not shielded from crises; they periodically experience crises.

Recent crises in schools and perceived public dissatisfaction of how the schools handled the crises signal that all is not well with crisis management in schools. The perceived public dissatisfaction suggests a variance in the level of expectations between the school and the school public on how crises are managed. Closely associated with the public dissatisfaction may be the absence of coordinated efforts to deal with the crisis, which manifests itself in various stakeholders often acting in isolation and in most cases getting in each other's way. Accordingly questions predicated on the school's ability to handle crises surface and the school's reputation is negatively affected creating a situation where the faith of the school public in the leadership of the school weakens. Eventually a climate of no confidence is created in the school leadership to lead the school in general and to carry out protracted reforms specifically.
Schools as social-political institutions thrive on the goodwill of the public hence the ability of the school to effectively handle crises increases the social capital of the school. Conversely, the social capital of the school diminishes when the public perceives the school as unable to handle crises. In an era of proliferation of the airwaves and heightened interests in what goes on in schools, what happens in a school can no longer be kept there. However, data about the extent to which senior high schools in the Cape Coast metropolis have effectively handled crises are nonexistent. The absence of such data makes it difficult for one to ascertain whether schools are properly positioned to handle crises. This condition is unlikely to change unless more is known about the best operating practices in handling crises by schools.

\section{Purpose of Study}

This study was an attempt to understand how senior high schools in the Cape Coast metropolis deal with crisis situations. Specifically, the study was intended to produce the following information about crisis management in senior high schools in the Cape Coast metropolis:

- Nature and impact of crises on the operations of the school and the response of the schools to the crisis situation.

- Level and amount of preparedness of senior high schools in the Cape Coast metropolis to deal with crises.

- Aftercare services to crisis situations in senior high schools in the Cape Coast metropolis. 
The study was framed by the key research question: how do senior high schools in the Cape Coast metropolis deal with crisis situations?

\section{Review of Related Theory}

A school is usually expected to be a safe place for teaching and learning to take place, however, unexpected events that may disrupt the normal life in the school could occur. Various authors (e.g., Kowalski, 2005; Moriarity, Maeyama; \& Fitzgerald, 1993; Trump, 1998) have identified crises in schools to include but not limited to situations and incidents involving the death of a student, a staff member, or a community member whose death affects a significant portion of the school population; natural disasters and major environmental crisis (i.e., fires, floods, rain storms, earthquakes); situation that involves a threat to the physical safety of students (i.e., school bus accident, structural failures in the school facility, abduction, violent acts); situation that involves a perceived threat to the emotional well-being of students; epidemics (food poisoning, water poisoning, flu); and negative media publication.

Ubben, Hughes, and Norris (2007) opine that the school has a responsibility to provide reasonable and prudent protection for its charges at all times. The school is responsible for taking all steps to promote the wellbeing of the students within the school and to guard the welfare of the staff. It behooves the school to develop a set of guidelines, if carefully followed, will result in protection for both students and staff. Such guidelines include the provision of information to prevent, prepare, and respond appropriately to unforeseen situations.

Parker (2008) suggests that school communities will be well positioned to cope with serious problems if they take time to prepare for crisis situations. before they happen. Parker further states that the level of preparedness of a school impacts how the students deal with crises in both the short and long term. Crisis situations, particularly those occurring during school hours, create a wave of panic and confusion and threaten the unity and comfortable familiarity on which students and families depend.

The Center for Mental Health in Schools at UCLA (2008) recognizes that given the complexity of crisis situations and varied reactions from stakeholder groups, the proper handling of school-wide crises is essential to minimizing negative impact on learning and recommends that schools adopt, implement, and institutionalize a set of crisis intervention procedures. The Center suggests that "a comprehensive crisis intervention approach provides ways for school personnel, students, and parents to return to normalcy as quickly as feasible, address residual (longer-term) psychosocial problems, and explore preventive measures for the future." (p. 7)

Quinn (2002) affirms the need for crisis intervention plans and recommends that individuals and subgroups with diverse expertise need to be involved in the planning and implementation of the crisis intervention plans. The plans will 
provide common strategies that schools will have ready to use in the event of a crisis situation. All who are involved should be provided with additional specialized in-service training. In developing crisis intervention plans, Trump (2000) avers that media coverage plays a major role in the management of crises and exhorts schools to pay particular attention to communication plan within the crisis intervention plan.

Schools can use the media as an effective communication vehicle for getting accurate information to stakeholders in a timely manner on efforts to mitigate crises. Communication, in and out of schools, is critical to meeting this expectation. Once the media become involved, schools face a public nightmare. Crisis can damage a school's reputation overnight and more importantly failure to communicate effectively during a crisis situation often produces a second-level problem for school officials (Kowalski, 2010). Kowalski, Petersen, and Fusarelli (2007) counsel administrators to prepare to communicate with the school public and the media and desist from using "no comment" when addressing especially the media during crisis a situation. They intimate that very often reporters and the public are suspicious that the "no comment" indicates that the administrators are attempting to conceal vital information.

Schonfeld and Newgass (2003) note experience teaches that schools can support and assist children and staff during and after a crisis situation. In the aftermath of a crisis, school-based intervention may be the most effective, logical, and practical way to provide assistance. This is particularly true if the school-based efforts are coordinated with other agencies.

\section{Methodology}

A basic interpretive study - understanding a phenomenon and the perspectives of the people involved and how they construct their worlds and the meaning they attribute to their experiences - was conducted to gather data from school heads of senior high schools $(n=8)$ in the Cape Coast metropolis. The school heads were purposively selected as their schools have recently experienced a crisis. Data were collected through semistructured interviews with the school heads of the selected senior high schools in the Cape Coast metropolis. The school heads were contacted and suitable days were scheduled for the interviews. The interviews were conducted over a period of one month, specifically, from July 5 to August 5 , 2011 . Each interview session lasted for about 50 minutes.

The interview protocol consisted of 15 main open-ended questions that addressed topics culled from suggestions for a linear approach to handling crisis: description of crisis; having a crisis management plan; ensuring security of the school during crisis; managing parents, media, and school public; disseminating information to stakeholders; providing aftercare services; returning school to normal operations; and documenting lessons learned from the crisis (Kowalski, 2010). Additional topics 
which emerged as a result of followup and probing questions also were addressed. The additional topics mainly were to elicit clarification on what had earlier been said by the school heads or have the school heads further expand on an issue that had earlier been addressed.

The interview data were coded and analyzed to identify recurring themes that were grouped under (a) addressing crisis situations, (b) preparedness of senior high schools in the Cape Coast metropolis to deal with crises, and (c) recovery after crisis. Credibility and dependability were assured through member checks; the school heads were asked to comment on the interpretation of the data collected and peer debriefing; a colleague scanned the raw data and assessed whether the findings were plausible based on the data collected.

\section{Findings and Discussion}

\section{Addressing crisis situations}

Findings on addressing crisis in the school focused on issues pertaining to the description of nature of the crisis, how the informant learned about the crisis, the nature of the response of the school to the crisis, and the perception of the informant regarding the degree of impact of the crisis on the operations of the school. Three major crises were identified by the study informants.

The study informants identified negative media publication as a crisis experienced in the school. The informants intimated that media publications that negatively impact the school's reputation were often times as a result of events in the school being blown out of proportion and taken out of context. A study informant indicated: "because the media are in a hurry to be the first to put out a story, when you tell them that you will need to do a further investigation before you give a statement to the press, they still proceed to publish the story without your version. In such situations, events tend to be misrepresented." The study informants stated that they experienced negative media publication at least once during the past academic year.

The informants learned about the negative media publication through various avenues (i.e., staff members, friends, family, district education officers). However, the predominant avenue for learning about the crisis was through a phone call from a friend. "A friend called in the morning and asked if I had seen a publication in one of the dailies? Another friend called and asked me to tune in to a radio discussion on my school."

The informants stated that they do not have in place an established communication plan showing communication pathways and protocols in the event of a crisis to communicate internally and externally. In response to how often they hold press briefings, the informants intimated that the nature of their employment contract does not permit them to hold press briefings nor to directly issue press statements to media houses. They are expected to give situational reports to their immediate governing authority who makes a determination whether to issue a press statement or not. On the other hand, the informants mentioned 
that they make efforts to provide the staff with details of any ongoing developments associated with the crisis either at formal gatherings such as staff meetings or at informal gatherings.

However, Kowalski (2010) holds a contrary view on absence of communication plan in the schools. He argues that a school should have a communication plan detailing how communication should be carried out during and after crisis. In addition, he suggests that schools should have designated spokesperson or persons to reduce the likelihood of conflicting messages reaching the school public during a crisis.

The study informants opined that negative media publication had a significant impact on the life of the school. An informant stated: "negative media publication is a source of worry. The stakeholders, especially the parents and the alumni, readily believe the stories they read and even before they crosscheck with the school, they start reacting violently towards you." The informants unequivocally stated that negative media publications about the school affect every aspect of the school's life and weaken the morale of everyone in the school.

Social capital in the form of public satisfaction is essential for the operations of the school.

The critical role played by positive school image in school effectiveness is supported by various researchers. For example, Bauman (1996) points out a positive association between public interest or satisfaction in a school and public support for the school. Similarly, Smith and Piele (2006) identify public support for schools as contingent on the degree of association with the school, which is influenced by the image one has of the school. Negative image erodes public support for the school.

Another school crisis experienced by the informants was a student leaving school for more than a day without permission. This type of crisis had been experienced by seven out of the eight informants. Students in the schools are to obtain explicit permission from the school authority (e.g. house master or mistress) before they leave the school's premises. "In our situation where we are running boarding institutions, when a student goes missing from school, you are not sure what has really happened to the student. Is the student playing truancy or has the student been abducted? These thoughts will give a person severe headaches." According to an informant, "we act in loco parentis because the students are entrusted into our care by the parents hence it is a worrying scenario when as school head you are unable to ascertain the whereabouts of a student. When a student leaves the school without permission, the student does not go home to the parents; instead the student goes to spend the time with friends."

The informants indicated that they learned of the crisis of a missing student from school through the senior house master. According to the study informants, the police is not contacted when a student goes missing from 
school; instead the parents of the student are informed of what had happened and briefed on efforts to trace the whereabouts of the student. In addition, various masters are assigned to interview selected students who are perceived to have information about the movement of the missing student. "We spare no effort in tracing the whereabouts of the student. The staff members continuously talk to students and ask probing questions and we are fortunate the approach has yielded good results in the past. The missing student is located and appropriate sanctions applied to him.

The study informants stressed that ensuring the safety and security of the students was of prime concern to them hence when a student goes missing it affects the entire school operation. Every staff is involved and normal school routine gets disrupted. The identification of failure to ensure the security of the students as a major crisis in the school is congruent with the postulate of Trump (1998). Trump argues that security in the school is essential in creating good learning environment and goes on to describe security as preventing and responding to criminal acts and severe misbehaviour on the part of students.

Death of a student or a person closely associated with the school was identified by the informants as the third major crisis that occurred in the school. The study informants $(n=4)$ who have experienced the death of a student on campus mentioned that it was very difficult to organize classes on that fateful day and the few subsequent days. According to one of the informants, "the tragic news of the death of a student brought all activities on the campus to a halt. Groups of persons were seen gathered at various points in the school discussing the demise of the student. Some were openly shedding tears. The entire atmosphere on campus was of a mournful nature. The school administration took a decision that there will be no classes on that day. Normal classes resumed after about four days in an atmosphere considered as being not the best for organizing effective teaching and learning."

As regards the death of a person closely associated with the school, one of the informants stated that when the news was received about the death of this prominent associate of the school and the authenticity of the news was verified, the normal school activities were brought to a standstill. The informant stated that though no one called for a halt to school activities, members of the school community: academic and non academic staff and students were in no mood to carry out any activity.

The study informants indicated that they were informed of the tragic news of the death of a student or a person associated with the school by a staff member. They further indicated that the schools do not have a designated staff to communicate such news to the school public; the tragic news was passed on by whoever heard it.

Also, the informants hinted that they did not have coordinated efforts among staff in responding to tragic news. The responses of the school community were influenced by the 
degree to which they were affected by the tragic news; staff and student reacted differently. However, one of the informants identified a specific means through which the school responded to tragic news of the death of a person closely associated with the school. "A general assembly of staff and students was convened and the sad news was formally passed on to the school. In addition to using the assembly to break the sad news to the school, it afforded us the opportunity to grieve together and console one another. We were not able to continue with the rest of the day's scheduled activities. I allowed people to express their emotions."

The informants also stated that even though the schools have counselors, they were not assigned key responsibilities during the crisis. The role of the school counselor was clearly defined and communicated to the school community and the informants believed that those who needed assistance knew who to contact.

\section{Preparedness to deal with crisis}

According to the informants, the schools do not have a documented crisis management plan that guided how they handled the crises. In addition, the schools do not have crisis response teams and do not organize drills to rehearse how to respond in times of crisis. However, the informants stated that they rely on the assigned duties and responsibilities of the various administrative positions in the school (e.g., housemasters or mistresses, senior housemaster or mistress, assistant heads) to deal with crisis. The finding that the schools do not have a crisis management plan is not congruent with as the work of various authors (e.g., Johnson, 2000; Parker, 2008; Riley \& McDaniel, 2000) on how schools prepare to handle crisis.

According to Brock, Sandoval, and Lewis (2001), a crisis management plan provides guidelines and protocols for addressing various crisis situations in a school. Parker (2008) acknowledges that there is no one size fits all kind of crisis management plan because each crisis situation requires special handling. He however, states that the presence of common strategies in a crisis plan that schools can have ready to use at a moment's notice, makes the possession of crisis management plan essential to handling a crisis.

A crisis management plan ensures that members of the school administration, staff, and key stakeholders are familiar with roles and processes in the event of a crisis. A crisis management plan facilitates a quick and coordinated response when crisis occurs (Poland \& McCormick, 2000). Fearn-Banks (1996) posits that a crisis management plan serves as a tool of preparedness and acts as the framework for quick response to a crisis situation. A crisis management plan assists with coordination of resources, which is critical in maximizing the positive efforts and programs within the school and community to not only intervene effectively during a crisis, but to prevent crisis situations.

In assessing their own level of knowledge, skill, and disposition on a 
continuum ranging from not being well prepared to being adequately prepared for responding to school crises, the study informants assessed themselves as being fairly prepared to handle crises. This finding is not consistent with the postulate of Seeger, Sellnow, and Ulmer (2003) who argue that effective and informed leadership at all levels is crucial to supporting students, families, and staff during and after a crisis. Additionally, school administrators should be well prepared and well resourced to handle crisis, for example, they can assist by funding continuing professional development activities in the area of crisis intervention.

\section{Recovery after crisis}

Findings dealing with recovery after crisis looked at the various aftercare services schools in the school and measures to return the school to normalcy. The study informants indicated that counseling services are available to the students. The schools have full-time school counselors assigned with the responsibility of taking care of the psychological and mental health needs of students. However, the school counselors do not provide services to the staff. Also, the school counselors have not been preparing teachers and other staff to assist with counseling services, especially with the immediate needs of crisis intervention. Finally, the informants stated that they do not have plans addressing concerted efforts at monitoring of students by staff to assess the emotional impact of crises on the students.
These findings are not consistent with the works of various authors (e.g., King, Price, Telljohann, \& Wahl, 2000; Riley \& McDaniel, 2000). The authors posit that the role of the school counselor is to provide direct counseling services to the students and the staff during and after crises. Additionally, the authors state that counseling support systems in schools are strengthened when school counselors prepare the staff to provide assistance with aftercare services. Kowalski (2010) points out that managing the aftermath of a crisis is probably the most ignored element of crisis management in schools. $\mathrm{He}$ opines that once the crisis is under control, professional counselors should assume greater role in providing services to both staff and students. He further admits that aftercare needs depend on the nature of the crisis experienced in the school, hence the need for creation of contingency plans for dealing with the aftermath of a crisis.

The informants indicated that they did not have laid down procedures to return the school to normal operations. They identified "time" as being a key element to guide when school operations return to normal. "As time passes and other activities assume prominence in the school, life in the school gradually returns to normal." Trump (2000) suggests that as soon as possible, the school should return to normal operations. According to Kowalski (2010), students are better helped to deal with crisis when they are able to follow a schedule. 


\section{Conclusion}

Senior high schools in the Cape Coast metropolis remain largely unprepared to handle a crisis. The schools have been engaging in firefighting approach in addressing crises. Despite the overwhelming emphasis in literature on the need for a crisis management plan, the schools do not have available a crisis management plan detailing prevention and response plans - coordinated and systematic institutional activities aimed at mitigating crises and ameliorating their impact on students when crises do occur.

Also, the schools have not taken proactive steps toward enhancing relationships and communication, especially with the media, before crises strike. The schools are inadequately prepared to address emergency notification of parents, handle internal staff communication, and cope with the demands of the media. Such failure on the part of the school had represented "crisis after the crisis" (Kowalski, 2005, p. 48) for school leaders. Rollo and Zdziarski (2007) intimate that how schools respond to a crisis can put a human face on the school. Gainey (2009) states that preparedness to address crises entails developing and implementing formal crisis-management plans, planning for two-way communication that builds relationships with internal and external stakeholders, and developing strategies for providing effective leadership within the culture of the school community.

\section{Recommendations}

The study recommends to school boards to assist senior high schools in the Cape Coast metropolis to develop a crisis management plan to be an integral part of the strategic plans of the schools. Also, this study provides limited insights into the relationship between the schools and agencies dealing with safety and security (e.g., Police Service, Fire Service, National Disaster Management Organization, Hospitals). This topic needs to be explored in greater depth. Finally, this study should be replicated in other GES designated districts and metropolis to determine if findings reported here are typical for the entire country.

\section{References}

Allen, M., \& Ashbaker, B. Y. (2004). Strengthening schools: Involving paraprofessionals in crisis prevention and intervention. Intervention in School and Clinic, 39 (3), 139-146.

Bauman, C.B. (1996). Governing education: Public sector reform or privatization. Needham Heights, MA: Simon and Schuster.

Brock, S. E., Sandoval, J., \& Lewis, S. (2001). Preparing for crises in theschools: A manual for building school crisis response teams (2nd ed.). New York: Wiley.

Center for Mental Health in Schools at UCLA. (2008). Responding to a Crisis at a School. Los Angeles, CA: Author. 
Gainey, B. S. (2009). Crisis management's new role in educational settings. Clearing House, 82(6), 267 -274 .

King, K. A., Price, J. H., Telljohann, S. K., \& Wahl, J. (2000). Preventing adolescent suicide: Do high school counselors know the risk factors? Professional School Counseling, 3, 255263.

Kowalski, T. J. (2005). Revisiting communication during crisis: Insights from Kenneth Trump. Journal of School Public Relations, 26(1), 47-55.

Kowalski, T. J. (2008). School public relations (4th ed.). Boston: Allyn and Bacon.

Kowalski, T. J. (2010). The school principal: Visionary leadership and competent management. New York: Routledge.

Kowalski, T. J., Petersen, G. J., \& Fusarelli, L. D. (2007). Effective communication for school administrators: A necessity in an information age. Lanham, MD: Rowan and Littlefield Education.

Merriam, S. B. (2002). Qualitative research in practice: Examples for discussion and analysis. San Francisco: Jossey-Bass

Moriarity, A., Maeyama, R., \& Fitzgerald, P. (1993). A clear plan for school - $\mathrm{c} \mathrm{r}$ i s i s management. NASSP Bulletin, 77(552), 17-22.
Parker, D. (2008). Addressing crisis situations: School emergency management planning Retrieved on May 19, 2011 from http://www.suite 101. com/content/ preparing-forproblems-a53926.

Pauchant, T., \& Mitroff, I. (1992). Transforming the crisis prone organization. San Francisco: Jossey-Bass.

Poland, S., \& McCormick, J. S. (2000). Coping with crisis: A quick reference. Longmont, CO: Sopris West.

Quinn, T. (2002). The inevitable school crisis: Are you ready? Principal, $\quad 81(5), 6$ 8.

Riley, P. L., \& McDaniel, J. (2000) School violence prevention, intervention, and crisis response. Professional School Counseling, 4, 120125.

Rollo, J. M., \& Zdziarski, E. L. (2007). The impact of crisis. In E. L. Zdziarski, N. W. Dunkel, \& J. M. Rollo (Eds.), Campus crisis management. A comprehensive guide to planning, prevention, response, and recovery (pp. 3 - 34). San Francisco: Jossey-Bass.

Schonfeld, D. J., \& Newgass, S. (September, 2003). School crisis response initiative. OVC Bulletin. Retrieved on May 19, 2011 from www.ojp.usdoj. gov/ove publications/bulletins/school crisis/ncj 197832.pdf. 
Seeger, M.W., Sellnow, T. L., \& Ulmer, R.R. (2003). Communication and organizational crisis. Westport, CT: Praeger Press.

Trump, K. S. (1998). Practical School Security: Basic Guidelines for Safe and Secure Schools. Thousand Oaks, CA: Corwin Press.
Trump, K. S. (2000). Classroom Killers? Hallway Hostages? How Schools Can Prevent and Manage School Crises. Thousand Oaks, CA: Corwin Press.

Ubben. G, Hughes. L, Norris. C. (2007). The principal: Creative leadership for excellence in schools. Boston, $M$ A: Pearson Education. 